\title{
Health Insurance and the Labor Supply Decisions of Older Workers: Evidence from a U.S. Department of Veterans Affairs Expansion
}

\author{
Melissa A. Boyle and \\ College of the Holy Cross \\ Joanna N. Lahey \\ Texas A\&M University
}

\begin{abstract}
This paper exploits a major mid-1990s expansion in the U.S. Department of Veterans Affairs health care system to provide evidence on the labor market effects of expanding health insurance availability. Using data from the Current Population Survey, we employ a difference-indifferences strategy to compare the labor market behavior of older veterans and non-veterans before and after the VA health benefits expansion to test the impact of public health insurance on labor supply. We find that older workers are significantly more likely to decrease work both on the extensive and intensive margins after receiving access to non-employer based insurance. Workers with some college education or a college degree are more likely to transition into selfemployment, a result consistent with "job-lock" effects. However, less-educated workers are more likely to leave self-employment, a result suggesting that the positive income effect from receiving public insurance dominates the "job-lock" effect for these workers. Some relatively disadvantaged sub-populations may also increase their labor supply after gaining greater access to public insurance, consistent with complementary positive health effects of health care access or decreased work disincentives for these groups. We conclude that this reform has affected employment and retirement decisions, and suggest that future moves toward universal coverage or expansions of Medicare are likely to have significant labor market effects.
\end{abstract}

\section{Keywords}

labor supply; job-lock; retirement; older workers; health insurance; VA; Medicare; veteran

\section{Introduction}

\begin{abstract}
In the current political and demographic landscape of the United States, it has become increasingly important to measure the impact of public health insurance on labor supply. Encouraging work at later ages would help to ease the rising strain on Social Security caused by the aging of the baby boomers coupled with increased life expectancy. At the same time, a push toward universal health care coverage might conflict with this policy goal, should
\end{abstract}

\footnotetext{
(c) 2010 Elsevier B.V. All rights reserved.

Publisher's Disclaimer: This is a PDF file of an unedited manuscript that has been accepted for publication. As a service to our customers we are providing this early version of the manuscript. The manuscript will undergo copyediting, typesetting, and review of the resulting proof before it is published in its final citable form. Please note that during the production process errors may be discovered which could affect the content, and all legal disclaimers that apply to the journal pertain.
} 
public insurance availability reduce the incentive for older workers to remain in the labor force. Economic theory predicts that public health insurance entitlement may affect job choice, income, and health. However, the magnitude and direction of the net effects of public provision on labor supply are ex ante ambiguous. Moreover, even where theory makes a clear prediction of the effect, empirical evidence has not always supported it. This paper evaluates the behavioral responses on labor force participation, full-time work, and self-employment from expanding publicly-provided health care for older Americans. We use new evidence from a U.S. Department of Veterans Affairs health care expansion to estimate the labor market effects of increasing public health insurance availability. By examining a health insurance expansion that is tied neither to employment nor to other public programs, we isolate the impact of an insurance offer on labor supply for older workers. Additionally, we are able to distinguish between two sometimes-competing effects of the receipt of public health insurance, the income effect from receiving the benefit and the ability to detach from employer provided health insurance.

Previous research examining the effect of public health care on work behavior has not provided clear answers. For example, government-provided health insurance that is not linked to employment acts as a positive income transfer for those with low earnings or high health costs because it is paid for via taxes, and the employed subsidize the not-employed. Theory therefore implies that universal insurance will likely decrease employment for these individuals. Empirical evidence for Medicaid, however, which not only is not conditional on employment but also is means-tested and therefore taxes earnings, is mixed (Winkler 1991, Moffitt and Wolfe 1992, Yelowitz 1995, Meyer and Rosenbaum 2001, Borjas 2003). Depending on the population studied and the methodology used, studies find a range of outcomes.

Adding to the theoretical complexity, other effects of government-provided insurance might lead to increases in labor supply or labor productivity. Health insurance may increase employment overall by improving health and reducing the work disincentive from other means-tested public assistance programs, which may also result in increased labor productivity. In line with this prediction, Gruber and Hanratty (1995) find that employment increased in Canada after the introduction of national health insurance. Additionally, studies examining the introduction of the U.S. continuation-of-coverage mandates, such as COBRA (e.g. Gruber and Madrian 1995), find resulting increases in job switching. By de-linking health insurance and employment (but not increasing income, since recipients must pay their own health premiums), these mandates may increase productivity not only by improving health but by enabling improved job matches, that is, reducing "job-lock". ${ }^{1}$

Most existing programs in the U.S. cannot provide the kind of policy experiment needed to distinguish the effects of expanding health insurance on the labor supply of older workers; in order provide this distinction, a policy change must not be directly tied to employment, income, or bundled with other program changes. In general, social insurance programs that increase income conditional on non-work, such as unemployment insurance (Krueger and Meyer 2002) and disability insurance (Bound and Burkhauser 1999), have been found to decrease employment. ${ }^{2}$ However, the theoretical predictions and the results of previous research are mixed for the employment effect of government-provided health insurance programs. These programs are often structured so that they provide a mixture of income transfers, employment subsidies and/or taxes, and improvements in human capital (via health), leading to ambiguous net effects on labor supply.

${ }^{1}$ For more information on job-lock, see Gruber and Madrian (2002).

2 In related work, Chetty (2008) further separates the employment reduction effects of unemployment insurance into a "liquidity effect" and a "moral hazard effect." 
Medicare is a health-care income transfer that is not linked to employment and could therefore shed light on the relationship between labor supply and health. Some studies (Lichtenberg 2002) suggest that Medicare improves health, though evidence is mixed depending on the time period studied (Finkelstein and McKnight 2008). The empirical effects of Medicare on labor market outcomes, however, are difficult to disentangle from those of Social Security and other programs linked to the normal retirement age. Most papers that study the Medicare-work relationship use structural estimation to suggest that an expansion of Medicare will increase retirement (Rust and Phelan 1997, Johnson et al. 2003, French and Jones 2008, Blau and Gilleskie 2008). Although these papers provide a solid theoretical framework for the question of what would happen to labor supply if older people were provided with health care at less than cost, our quasi-experimental approach allows for a more transparent empirical identification strategy.

A unique opportunity to better understand the effects of universal coverage on older workers' employment is provided by a major mid-1990s expansion in both the services offered and the population covered by the Department of Veterans Affairs health care system (VA). This expansion converted VA health care from a hospital-based system focused on treating veterans for conditions related to their military service to a comprehensive health care system with a focus on outpatient preventive care. In addition, VA health care coverage which was previously guaranteed only to veterans with serviceconnected conditions and low incomes, was offered to the entire U.S. veteran population. Comparing veterans to a control group of non-veterans before and after the policy change allows us to isolate the labor supply impact of a program that provides an income transfer and may have health effects for some recipients, but that is not tied to employment or income and is not bundled with other program changes. Provided that veteran and nonveteran health outcomes and other characteristics do not trend differentially over time due to causes unrelated to the VA expansion, this strategy enables us to isolate the treatment effect of expanding the availability of public health insurance. From a policy standpoint, the effects of this program change are likely comparable to the effects of expanding Medicare to Americans under age 65, a plan often proposed by politicians.

We find that the VA expansion decreases employment and increases part-time work among older recipients. In addition, it results in a drop in self-employment for men with lower levels of education and an increase in the probability of self-employment for more highly educated individuals. This outcome is consistent with a job-lock reduction (in which delinking health care from employment would increase transitions from paid work to more flexible but uninsured self-employment) dominating for men with more education, and the effect of an income transfer (since recipients no longer need either employer-provided insurance or the earnings from employment to protect against adverse health shocks) dominating for men with less education. Additionally, we find suggestive evidence that veterans from certain disadvantaged groups increase their labor supply as a result of gaining public insurance, implying that for these groups, health improvements or decreased work disincentives from this insurance expansion complement work. Finally, we posit that health insurance may be one reason that retirement rates conditional on age are higher in countries with national health insurance.

The paper is organized as follows: Section II provides a theoretical background for the effects of health insurance on employment, Section III describes the VA program in detail, Section IV describes the dataset and empirical strategies, Section V provides results, Section VI discusses and provides implications and Section VII concludes. 


\section{Predicted Effects}

The impact of VA health insurance on labor supply is theoretically ambiguous. First, an offer of public health insurance acts as an income transfer. With higher income but the same underlying wage rate, theory predicts that on average, labor hours will fall. Some workers may move from full- to part-time work because they no longer need the income to pay for insurance premiums or out-of-pocket medical costs, and thus substitute leisure for work. Similarly, in response to the income transfer, workers may drop out of the labor force entirely, either temporarily or permanently (i.e. earlier retirement). Finally, the income transfer would potentially lead to a movement out of self-employment, as individuals who were previously working in order to pay for health costs out-of-pocket will no longer need to do so.

Along with acting as an income transfer, the offer of public health insurance should reduce job-lock. Workers are no longer reliant on their employers for insurance coverage, and thus fluidity in the labor market should increase. Workers have the flexibility to change to job positions offering higher wages but lower benefits, and more productive employer-employee matches may result. Older workers who are no longer job-locked because of insurance coverage will have the option of retiring earlier or transitioning to retirement by moving to part-time work without benefits. Workers who prefer self-employment but were previously unable to afford insurance in the non-group market or payment of health costs out-of-pocket now have the flexibility to become self-employed. Thus, the reduction in job-lock may lead to an increase in self-employment that runs counter to the decrease caused by the income transfer, especially for those groups for whom employment provides consumption value or less disutility than for other groups.

However, while both a job-lock reduction and an increase in underlying wealth due to an income transfer would predict a drop in overall labor hours on average, it is also theoretically possible that labor supply will increase for some groups. An uninsured (or inadequately insured) worker with a chronic health condition that may previously have forced him out of the labor force may be able to continue working if the newly-acquired insurance improves his health. The addition of health insurance may also allow workers on the margin of applying for Social Security Disability Insurance (SSDI), and thus receiving Medicare after two years, to stay in the labor force. ${ }^{3}$ Hence, labor supply might increase for some groups after the expansion, improving the productivity of the unhealthy on the margin of working by increasing their health capital or increasing work incentives. ${ }^{4}$

It is important to determine the extent to which providing government insurance causes employment changes via an income effect channel versus by diminishing job-lock. Because job-lock inefficiently locks workers into less productive job matches, reducing these rigidities results in greater productivity overall. The welfare implications of a public insurance-induced income effect are less clear. If labor supply falls because of an income effect, even though the individual utility of those affected increases (because the individual has been provided with a free good), providing this additional income may not be the best use of government resources. This is especially true if it leads to spill-over spending from other government programs such as Social Security. An income effect may also cause negative productivity spillovers to society, particularly if it is difficult to substitute for workers encouraged to leave career jobs because of this insurance. On the other hand, given rigidities in the labor market, overall social welfare may increase even with declining labor

\footnotetext{
3 Thanks to David Autor for recognizing this possibility.

${ }^{4}$ Note that an increase in health is equivalent to an increase in the relative wage since work is no longer as painful. As such, for groups not at the margin, the attractiveness of leisure may increase and hours may go down.
} 
supply among some groups (e.g. if this insurance allows unhealthy liquidity constrained individuals or expensive workers who are difficult to fire because of age discrimination laws to cut down on full-time work). ${ }^{5}$

An event study graph in Figure 1a shows annual predicted probabilities of not working for veterans and non-veterans with controls for age. Figure $1 \mathrm{~b}$ shows the same information with a more complete set of demographic controls. ${ }^{6}$ In Figure 1a, there is little difference in trends in not working between veterans and non-veterans in the pre-period and a clear increase in the probability of not working for veterans relative to non-veterans in the postperiod. Figure $1 \mathrm{~b}$ is similar, but shows a slightly larger gap between the two groups in both periods, with a larger difference in not working rates in the post-period than in the preperiod. These charts suggest that the VA program did have differential effects on labor market outcomes for veterans compared to non-veterans and serve to guide our main results.

\section{Description of VA Program}

The Department of Veterans Affairs (VA) health care system began over 70 years ago as a hospital system established to provide specialty care to veterans with conditions resulting from their military service. Over time, the system expanded to offer care to low-income veterans. VA primarily provided inpatient care, with outpatient services for non-serviceconnected conditions only available as follow-up to an inpatient stay. ${ }^{7}$

In 1996, however, the U.S. government began a major overhaul of this health care system in an effort to catch up with progress in private-sector medicine. During this time, VA health care began to shift from a hospital-based specialty-service provider to a comprehensive health care system with a focus on primary care and preventive medicine. This change resulted in a 44 percent decline in the number of VA inpatients between 1989 and 1999, and a 66 percent increase in the total number of outpatient visits over the same time period (Klein and Stockford 2001). During this time, VA's resource allocation system was also redesigned. VA began distributing its health care budget using a capitated, patient-based formula as in the HMO model. ${ }^{8}$ VA anticipated that the increased efficiency from these changes would result in significant reductions in costs per patient and in staff. VA thus felt that it would have the resources available to administer the entire veteran population and relaxed its rules on eligibility for care. Prior to the reform, VA guaranteed care only to veterans with service-connected conditions or low incomes. After the reform, all veterans became eligible for VA health care (U.S. General Accounting Office 1999).

Prior to utilizing VA services, veterans were required to fill out paperwork enrolling in the program. However, enrollment did not automatically imply that veterans utilized VA health care; veterans could enroll to guarantee the ability to utilize VA services in the future. By 2002, 6.6 million veterans had enrolled and VA's patient load had increased to 4.3 million (up from 2.6 million veterans in 1995) (U.S. General Accounting Office 1996, 2003). ${ }^{9}$ During our study period, enrolled veterans were placed in one of seven priority groups. Veterans in group one, those with service-related conditions resulting in disability of 50

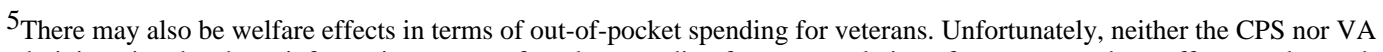
administrative data have information on out-of-pocket spending for our population of veterans, so these effects are beyond the scope of this study. Boyle (2008), using the Medicare Current Beneficiary Survey, does find that out-of-pocket spending on prescription drugs decreases for those over age 65 as a result of gaining VA coverage.

6 The set of controls includes age, race, education, marital status and Census region dummies.

${ }^{7}$ For additional detail on VA health care and the associated reforms, see Boyle (2009).

8 In a capitated payment system, the health care provider is reimbursed a flat dollar amount for each patient regardless of the services provided.

${ }^{9}$ Prior to the reorganization, there was no formal enrollment system, so we cannot examine changes in enrollment, only changes in users.
} 
percent or higher, were considered the highest priority for treatment and veterans in group seven, those with incomes above VA determined thresholds and no service-connected disabilities, were considered the lowest priority. Care remained free for all previouslyeligible veterans (priority groups 1-6). Newly-eligible (group 7) veterans were required to pay modest copayments. ${ }^{10}$ During the time period examined in this study, the priority groups were used only for enrollment purposes and determination of copays; for those enrolled, routine care appointments were provided on a first-come first-served basis. ${ }^{11}$ Boyle (2009) examines the impact of the VA overhaul on veterans' health care utilization and health outcomes and finds that between 35 and 70 percent of new VA health care users are individuals who drop private health insurance plans, something that may have been linked to leaving full-time employment.

The VA restructuring affects the availability of health care for the entire veteran population. For non-poor, non-disabled veterans, the policy change constitutes the introduction of a form of non-employer-provided health insurance that was previously unavailable. Even for the previously-eligible (i.e., low-income or disabled) segment of the veteran population, this policy change results in a significant, exogenous change in health insurance status because the reorganized VA is a health care provider much more similar to what was available in the private sector. Thus, even for previous users of VA care, the policy change resulted in the introduction of health care benefits that are more substitutable for private care than anything provided under the old system. We therefore utilize this exogenous introduction of an outside health insurance option for U.S. veterans, using all veterans in our universe as the treatment group, to estimate the impact of publicly provided health insurance on individuals' labor supply choices.

\section{Data and Empirics}

\section{A. Data}

We use data from the Census Bureau's March Current Population Survey (CPS) for the years 1992 through 2002. The CPS provides consistent annual information on employment and demographic controls, including veteran status, throughout our time period. A limitation to this set, and indeed to most pre-1996 surveys is the lack of consistent standardized data on health insurance receipt across the entire period. ${ }^{12}$ Thus, while we are able to clearly estimate the impact of the policy change on labor supply, we cannot accurately test for changes in or by insurance status. We utilize a difference-in-differences estimation strategy to compare the labor supply choices of veterans and non-veterans before and after the restructuring of VA health care. Since we are interested in workers on the margin of not working (i.e. approaching retirement), we limit the sample to individuals ages 55 through $64 .{ }^{13}$ Additionally, because of the small number of female veterans in this age cohort, we

\footnotetext{
${ }^{10}$ For 2002 , the copay was $\$ 7$ for each prescription for a 30-day supply (this copay was $\$ 2$ through 2001 ). Copays for outpatient visits were $\$ 15$ for primary care, and for specialty care outpatient visits (outpatient surgery, audiology and optometry, etc.) the copay was $\$ 50$. Preventive care (flu shots, hepatitis C screenings, radiology services, electrocardiograms, etc.) cost nothing. (VA Fact Sheet, 2002)

${ }^{11}$ In other words, the priority groups did not imply differential access to care for different veterans during the years of our study, but rather were in place as a safeguard should VA run into future budget shortfalls. Beginning in 2003, VA determined that its budget was not large enough to allow it to continue offering care to all veterans. The lowest-priority group (the newly-created priority group 8 , which included non-disabled non-poor veterans not previously enrolled in the system) was then denied care.

${ }^{12}$ Unfortunately, the CPS was not designed as a health insurance survey. Although insurance information is recorded, the variables measuring health insurance coverage go through several changes during this time period in an effort to make the questions less ambiguous and to reduce known undercounting (Fronstin 2000, Nelson and Mills 2001). Results on and by insurance status are available from the authors upon request.

${ }^{13}$ Although it is not uncommon for individuals to continue work past age 64, eligibility for Medicare at age 65 will alter the impact of other public health insurance on the work decision. In general, significance of results is slightly stronger if we limit to those age 50-64 rather than 55-64, possibly because of a larger sample size. We use the more restricted sample in order to be consistent with the previous job-lock literature.
} 
restrict our sample to include only males. With these restrictions, the treated population is therefore male veterans ages 55 to 64 , and the control group is male non-veterans in the same age group. Since changes in VA health care were implemented throughout 1996 and 1997, we define 1992-1995 as the pre-policy period and 1998-2002 as the post-policy period. ${ }^{14}$

The CPS allows us to study labor market outcomes such as labor force or employment exit, and movement into part-time work or self-employment. In addition to information about employment in the current year, the survey questions individuals about their labor market participation during the previous year. In order to isolate the effect of the policy change on individuals' decisions to alter their labor market behavior, we restrict our sample to those who report working at least one week in the previous year. ${ }^{15}$

\section{B. Main Specification}

We use a probit model ${ }^{16}$ to estimate the following equation:

$$
\mathrm{y}=\beta_{0}+\beta_{1} \text { veteran }+\beta_{2} \text { veteran }{ }^{*} \text { post }+\mathbf{X}^{\prime} \beta_{3}+\delta_{\mathrm{t}}+\sigma_{\mathrm{s}}+\varepsilon
$$

The dependent variable, $y$, includes indicator variables for labor supply outcomes including not working, self-employed, and working part-time. The variable not working is 0 if the individual is employed and 1 otherwise. ${ }^{17}$ Several part-time variables were tested. The parttime variable reported is coded as 1 if the number of weekly hours worked is between 0 and 35 hours, and 0 if the individual works more than 35 hours. Alternate specifications for parttime provide similar results. Self-employed is an indicator that is equal to 1 if the class of worker is self-employed (either incorporated or not incorporated) and 0 otherwise.

Among the independent variables, veteran is a dummy equal to 1 if the individual has been honorably discharged from active military duty, post is a dummy equal to 1 in the postpolicy period, ${ }^{18} \boldsymbol{X}$ is a vector of individual characteristics including age, race, marital status, education, industry and occupation dummies, and indicators for employer-provided health insurance and pensions in the previous year and $\delta_{t}$ is a full set of year dummies while $\sigma_{\mathrm{s}}$ is a full set of state dummies. State dummies and year dummies account for heterogeneity in veteran take-up by state and time; this heterogeneity could be caused by local economic conditions making the program more attractive or variation in the degree to which the

\footnotetext{
${ }^{14}$ In January 2003, VA again revised the rules for obtaining health care. We therefore end our study period in 2002. Due to concern that particular Vietnam Era veterans are affected by a 2002 change that categorized diabetes as a war-related injury for veterans who may have been exposed to Agent Orange (Duggan et al. 2006, Autor and Duggan 2007) we have also estimated all equations restricting our post-period to 1998-2001. Selected results of this exercise are shown in Table 7, column (3). Coefficient magnitudes are nearly identical when 2002 observations are removed from the dataset and significance does not change. Additionally, the employment status variable in the CPS underwent minor changes in 1994. Our results are also robust to the removal of years prior to 1995, as shown in Table 7, column (4).

${ }^{15}$ This strategy is consistent with many studies in the job-lock literature, including Gruber and Madrian (1995). We find that restricting our sample to individuals who report working at least 10 weeks in the previous year produces very similar results, as shown in Table 7, column (5). Regressions on the whole sample (i.e. including individuals that did not work in the previous year) also produce results that are very similar as shown in Table 7, column (8).

16 Multinomial logit estimation produces very similar results. Select marginal effects from multinomial logit estimation for the sample in our main specification are reported in Table 7 column (6). Results using multinomial logit estimation to explore other labor market transitions are presented in Section V part B.

${ }^{17}$ The survey also includes a self-reported retired variable but we do not report this outcome for a number of reasons. Self-reported retirement is not exclusive of working and often includes individuals who are still working full or part-time but no longer in a career job, still working at the career job but receiving retirement benefits, or involuntarily unemployed but over some age threshold, among other possibilities. Unemployed older workers hoping to return to the labor force may or may not claim to be retired. For more discussion of definitions of retirement see for example Berkovec and Stern (1991), Gustman and Steinmeier (1984, 1995) or Araiza (2004). Additionally, the self-reported retired variable is available only for $1994 \mathrm{on}$.

${ }^{18}$ Results are nearly identical when 1996 and 1997 data are included with a value of .5 for the post variable.
} 
program was publicized to veterans in different regions. Because the propensity for separating from the labor force will vary with type of employment and benefits offered, we include indicators for industry and occupation in the previous year and for employerprovided health insurance coverage and inclusion in a pension plan in the previous year in some specifications. Standard errors are adjusted for non-independence of the errors within the veteran*year group.

\section{Identification assumptions}

As with any difference-in-differences model, certain assumptions must be satisfied in order for a causal interpretation of the results to be valid. In our quasi-experimental setup, it must be the case that (1) veterans and non-veterans are reasonably similar before the health care expansion, (2) only veterans are affected by the VA expansion, (3) no other shocks occur during this time period that differentially affect veteran and non-veteran labor supply choices, and (4) that the two populations would not trend differentially in the absence of a policy change due to unobservable factors.

Summary statistics in Table 1 demonstrate that the veteran and non-veteran samples are reasonably comparable in the pre-period. The average veteran is more educated, and slightly more likely to have employer-provided health insurance than the average non-veteran. Because veterans are slightly older in the pre-period, and the age composition of veterans compared to non-veterans is changing over time, it is important to include controls for age in all specifications. Veterans are more likely to be not working than non-veterans in the preperiod sample.

We may be particularly concerned about external validity if we believe that veterans and non-veterans are affected differently by receiving health insurance (for example, if they had worse health or different propensities to work on average). Calculations available from the authors using the National Health Interview Survey find that, on average, there do not appear to be health differences between veterans and non-veterans in the pre-period for the cohorts examined in this study. ${ }^{19}$ Additionally, by restricting to individuals recently in the labor force, we effectively limit our sample to veterans who are not suffering from catastrophic service-related conditions. Finally, according to Greenberg and Rosenheck (2007) and Angrist and Chen (2007), there is little to no difference in work behavior between veterans and non-veterans in our cohort.

Assumption (2) is valid because non-veterans were not affected by the expansion. The offer of VA insurance was only extended to veterans and did not include additional family members. Some veterans already had access to VA health insurance, but, as detailed previously, the insurance was much less comprehensive than the coverage post-expansion, so those individuals are still substantially impacted by the change. Additionally, we are only measuring the effect of an offer of health insurance, not the actual take-up of health insurance. Many veterans did not sign up for VA insurance even though it was offered to all. As a result, the effect of this expansion is likely an underestimate of expanding publiclyprovided health insurance. In the sense of pure insurance theory, veterans were insured once they were offered VA coverage whether or not they formally enrolled because they were led to believe they could sign up at any time if the coverage was needed. Thus even if they were

\footnotetext{
${ }^{19}$ If anything, it appears that on average veterans are slightly healthier in both periods using the NHIS data. In previous literature, Wolinsky et al. (1985) finds that veterans have significantly higher self-reported health ratings, though the point difference (3.29 vs. 3.24 on a 4 point scale, with 4 being the best) is not large and he does not control for gender differences. Slightly better health among veterans may bias us towards finding no results. There is a substantial literature examining the types of veterans who used VA clinics prior to the expansion. This literature finds that the subset of veterans who were users of VA clinics were in poorer health than a crosssection of non-veterans. However, during this time-period VA insurance was primarily available to a selected group of veterans: poor veterans and those with service-related disabilities. Both of these groups are more likely than average to be in poor health or disabled.
} 
not formally insured, they could tap into the insurance in an economic sense, and were treated in the first stage. ${ }^{20}$ However to the extent that some veterans may have been unaware of the insurance, our results provide an underestimate of the behavioral effect of full government coverage.

The third assumption would be violated if something else is affecting veterans and nonveterans differentially besides this expansion. Policy changes in 1996-1997 such as welfare reform are unlikely to affect older male veterans differently than older male non-veterans. Indeed, only 57 observations in our sample report receipt of any welfare/public assistance during the entire time period. Finally, there may be a worry that there are unobserved systematic differences between the treatment and control groups that would cause the treatment and control to trend differently in the post-period. We find no evidence of preexisting trends in a falsification exercise using pre-policy years. We have run several other specification checks including a model in which all controls are interacted with the veteran indicator and a model in which we use propensity score matching to draw a comparable control sample. These tests support the assumption that there are no systematic differences between the two groups and we discuss them in more detail in the results section under robustness checks.

\section{Results}

\section{A. Main Results}

Our primary results are detailed in Tables 2 and 3. Reported coefficients for all regressions are probit marginal effects. These regressions estimate equation (1) and are reported with and without controls for characteristics of the employer in the previous year. Results are qualitatively similar with and without these controls, although the magnitude of the coefficient of interest (the coefficient on veteran*post) varies slightly across the two specifications. In the remainder of the paper we discuss the regressions with the full set of controls because they account for possible heterogeneity in propensity for separating from the labor force by employer type.

As theory would predict, providing free health insurance outside of employment decreases work for older workers. As a result of gaining VA coverage, the probability of working drops by .45 percentage points for an individual with average characteristics, as detailed in Table 2, column (2). ${ }^{21}$ Relative to the pre-period average, this is about a $3.33 \%$ increase in the probability that an older worker ceases work. While the magnitude of this estimate is not large, it is likely to be a lower bound because while we measure the effect on the entire veteran population, only about a quarter of U.S. veterans actually enrolled in the VA system during our study period. ${ }^{22}$ The effects are therefore likely to be attenuated by the large number of veteran non-users, some of whom may have been unaware of their eligibility to use the VA system. It is not clear what proportions of unenrolled veterans are unaware of their eligibility, not interested in ever using VA care, or relying on the option of enrolling at a later date should they desire VA care. It is possible that awareness may be different across

\footnotetext{
${ }^{20}$ Therefore, although only roughly $25 \%$ of veterans enrolled in the new VA program, multiplying our intent-to-treat results by four would be an overestimate of the true treatment effect, since in the pure insurance sense, all veterans are treated during this time period We estimate and discuss bounds on the true effect in Section VI. In a 2001 survey, $22 \%$ of veterans who did not sign up for VA said they did not sign up because they were not aware of the program (Department of Veterans Affairs, 2002b).

${ }^{21}$ These results are robust to removal of state dummies and different combinations of controls in the main specification. As predicted by the different age composition of the two groups, results attenuate dramatically and in some cases change sign when age dummies are omitted.

${ }^{22}$ As mentioned above, any veteran wishing to use VA care must first sign-up for benefits or "enroll" in the system. During our study period, some veterans enrolled but did not actually subsequently use VA care. The fact that these individuals enrolled indicates awareness of their eligibility and a potential desire to access the system at a later point in time.
} 
different subsets of the population, thus biasing the magnitude of our results. It is unclear whether advantaged veterans would have greater knowledge of the policy change through better information access or if connections to social services would provide better information access for less advantaged veterans. ${ }^{23}$

As reported in Table 2 column (4), our results also suggest an increase in the use of bridge jobs, which are jobs (often part-time) that people transition to after retiring from a main job (Ruhm 1990). We estimate a 0.89 percentage point increase in the probability of working part-time, which is an $8.40 \%$ increase relative to the pre-period veteran average for our regression sample. Similarly, in results available from the authors, veterans work on average between .2 and .4 fewer hours per week upon receipt of health insurance.

We also examine the effect of public insurance receipt on the probability of selfemployment. A story consistent with job-lock would predict an increase in (or at least no effect on) self-employment. This is because prior to gaining public insurance, some individuals who preferred self-employment might have remained in a current full-time employment situation in order to retain health benefits. On the other hand, since the public insurance is an income transfer for beneficiaries, the program could decrease selfemployment as recipients potentially no longer need the extra income to self-insure (or pay for) health risks. In Table 2, columns (5) and (6), we find a negative but insignificant effect of health insurance receipt on self-employment.

However, there may be heterogeneous effects of gaining health insurance across different education levels; those with higher education may be more likely to be job-locked by health insurance while those with less education are more likely to be credit constrained. When we cut the sample by education group, there are two opposite and significant effects for individuals with low and high levels of education. As demonstrated in Table 4, panel I, men with a high school diploma or less are 1.6 to 2.6 percentage points less likely to be selfemployed upon receipt of VA health insurance, a decrease of $8.5 \%$ to $13.8 \%$ from the preperiod average, and men with some college education or bachelor's degrees are 2.2 to 3.3 percentage points more likely to be self-employed, an increase of $10.3 \%$ to $15.4 \%$ relative to the pre-period average. ${ }^{24}$ These results suggest that the income effect of health insurance dominates for those with less education, and the job-lock effect dominates for those with more education. ${ }^{25}$

Finally, it is important not to take the results on leaving employment as an indication that providing health insurance to these older workers is simply a productivity diminishing transfer to that group. There are potential distributional differences in how people are affected; in particular, those in poor health might be more likely to see their health improve and their labor supply increase as a result of the health care expansion. ${ }^{26}$ To test for this possibility, we separately examine the outcomes for subgroups who typically exhibit worse health than average. For example, unmarried men in this age group are more likely to be in

\footnotetext{
${ }^{23}$ If information transfer for expansions of other programs like Medicare was similar to that for the VA system, then we would expect similar effects across groups. It is, however, likely that there would be stronger knowledge across all groups in the case of a Medicare expansion, by the nature of it being a nation-wide program likely to generate large-scale publicity. If that is true, then our results may underestimate the overall treatment effect, but potentially overestimate differences between groups.

${ }^{24}$ Education results with graduate degree-holders included are similar to those without. However, when the sample is limited only to those with graduate degrees the sign is sensitive to specification chosen. We therefore do not include graduate degree-holders in the reported regressions. We believe that those with post-baccalaureate education are less homogenous with respect to behavior than those in the other groups, but sample sizes are not large enough to determine how they differ.

${ }^{25}$ Le, Anh T. (1999) has a literature review of the empirical evidence that more educated people have a higher probability than less educated of choosing self- employment. Lucas (1978) provides a theoretical background.

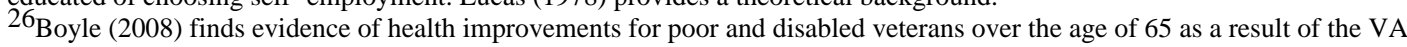
expansion.
} 
poor health than married men (Lillard and Panis 1996). Additionally, being below the means test may be highly correlated with poor health (Kiuila and Mieszkowski 2007). We find some positive work outcomes for these disadvantaged (i.e. unmarried or low-income) vets after they receive the health insurance offer. The first panel of Table 3 provides results for single men. Single veterans are less likely to be self-employed and less likely to be working part-time as a result of the policy change. The second panel of Table 3 provides results for those below the means test. Low-income veterans are less likely to be not working after the health insurance offer and expansion. A caution must be offered with the means test results; veterans below the means test already had access to VA health insurance, but as described earlier, this insurance was not comprehensive. Additionally, as mentioned previously, the extent to which the offer of VA insurance may differentially affect these subgroups is unclear.

Nevertheless, combined, these results are consistent with a situation in which increased medical care for more economically disadvantaged groups leads to health improvements or a reduction in the work disincentive associated with other means-tested programs and a corresponding increase in the ability to work. This result is consistent with some Medicaid literature that finds health increases and positive labor market effects from Medicaid among the poorest populations (Currie and Gruber 1996, 2001, Moffitt and Wolfe 1992).

Additionally, we may be underestimating these positive employment effects because although some conditions will improve immediately with treatment, some conditions may take time to show improvement.

\section{B. Intensity of Treatment and Joint Labor Market Transitions}

1. Intensity-As discussed above, certain veterans were eligible for VA health care prior to the policy change. Previously-eligibles (those with service-connected disabilities or low incomes) still have the potential to be affected by the change, since the types of health services available became much more comparable to those covered by employer-provided health insurance. Even so, we would expect to see stronger effects of the policy change on newly-eligible veterans, who go from having no outside insurance to full coverage under the public program. Consistent with this expectation, in the second panel of Table 3 we report results for individuals whose household income in the previous year was above the VAestablished means test cutoff and find that they are generally stronger than results for the entire group. Moreover, the coefficients switch signs from the main results for those below the means test. These differences support the conclusion that the behavioral changes consistent with an income effect from newly available insurance are concentrated among those for whom it is, in fact, newly available.

It is also possible that married veterans are impacted differentially depending upon their wives' access to employer-provided health insurance. There are two possible ways in which a wife's access to employer-provided coverage may affect a veteran's labor supply. On the one hand, because VA insurance only covers veterans and not their families, wives without their own employer-provided coverage are likely to still depend on coverage through their husbands' employers. ${ }^{27}$ Thus, a veteran whose wife has her own employer-provided health insurance may be more likely to reduce his labor supply since he is free to drop his private coverage in favor of VA coverage without risking his wife's insurance status. On the other hand, a veteran whose wife has employer-provided insurance may have been less "joblocked" in the first place because of the ability to utilize coverage through his wife's

\footnotetext{
${ }^{27}$ In cases where the veteran is catastrophically disabled or dies as a result of military service, the spouse and other dependents do become eligible for VA care under the CHAMPVA program. This is not relevant in our study, however, as catastrophically disabled veterans will not be in the work force.
} 
employer. Thus, the offer of VA insurance may have less of an impact on labor supply for these individuals.

As shown in Table 3, panel III, men whose wives claim to be included in an employer health plan in their own names are more likely to report not working as the result of insurance, and those with wives who do not have employer provided health insurance are slightly less likely to report not working, and these results are significantly different across the two groups. Comparing husbands with working wives to husbands without, we find the same pattern. ${ }^{28}$ Additionally, restricting to a sample of single men (who do not have to worry about spousal coverage) and men whose wives work, provides an effect of receiving health insurance that is about 10 times the magnitude of that for the entire sample, as shown in Table 4, panel II. These results suggest that the "covering wife" effect dominates the "being covered by wife" effect, which we might expect given that historically in these cohorts the husband is more likely to be the primary earner. Given that in general wives are younger than their husbands, any expansion of government insurance such as Medicare that includes age limits on coverage will also have this "covering wife" effect until the wife reaches the age limit specified by the program. ${ }^{29}$

2. Joint Labor Market Transitions-For consistency with the empirical literature on job-lock, the main results reported in Table 2 examine the effect of the VA policy change on individuals in the labor force. ${ }^{30}$ However, there may be interesting effects on other labor market transitions, especially with the increasing trend towards "unretirement" among older men (Maestas forthcoming). We therefore use a multinomial logit framework to examine the impact of insurance receipt on transitions into and out of full- and part-time work and selfemployment. For each population considered, the multinomial logit model allows us to jointly estimate the probabilities of transitioning into not working, part-time work for an employer, full-time work for an employer, and self-employment, as a result of gaining access to VA health care. We estimate the following equation:

$$
\text { workchoice }=\beta_{0}+\beta_{1} \text { veteran }+\beta_{2} \text { veteran }{ }^{*} \text { post }+\mathbf{X}^{\prime} \beta_{3}+\delta_{\mathrm{t}}+\sigma_{\mathrm{s}}+\varepsilon
$$

where workchoice is coded as $0,1,2$, or 3 if the individual is working full-time, working part-time, self-employed, or not working, respectively. All other variables are defined as in equation (1) above. Marginal effects from multinomial logit estimation are reported in Table 5 .

Column (1) of Table 5 examines the effect of VA insurance on those reporting zero weeks of work in the previous year. Individuals not working in the previous year are statistically significantly more likely to work at all in the current year with an offer of public health insurance. They are also more likely to work part-time as a result of this insurance receipt and are slightly more likely to be self-employed. The coefficient for full-time work is statistically insignificant, though the marginal effect is negative (but extremely small). Results for individuals who worked 2 weeks or fewer in the previous year are qualitatively similar. These results are consistent with the suggestion that some individuals out of work

\footnotetext{
$2857 \%$ of veterans in the sample have wives who are employed. Results are available from the authors upon request.

${ }^{29}$ Coefficients for other outcomes may not be significantly different because the effects are clouded by the fact that wives with health insurance of their own often must continue working to keep that health insurance and the decision to retire is often jointly determined between husband and wife (Coile 2004).

${ }^{30}$ For example, this is the strategy used by Karoly and Rogowski (1994), Gruber and Madrian (1995), Hurd and McGarry (1993), Madrian and Beaulieu (1998), Johnson, Davidoff and Perese (2003), and Rogowski and Karoly (2000). Table 7, column (8) provides the regression results for the not working outcome for the full CPS sample of males age 55-64, not conditioning on labor force participation in the previous year.
} 
because of poor health may be able to return to work part-time once receiving health insurance. They are also consistent with the possibility of individuals no longer needing to keep their incomes artificially low in order to qualify for means-tested programs such as federal disability programs or VA health care pre-reform.

Column (2) examines the effect of VA insurance on those working full-time in the previous year, where full-time work in the previous year is defined as working at least 35 hours per week on average and at least 40 weeks in the previous year. For individuals working fulltime in the previous year, there is a significant and relatively large (1.1 percentage point) reduction in the probability of working in the current year which is consistent with our main results. There is also a 1.2 percentage point reduction in the probability of working full-time in the current year. Coefficients for part-time and self-employed are positive but statistically insignificant.

Finally, column (3) reports the results for those working part-time in the previous year, with part-time defined as fewer than 35 hours per week for at least 40 weeks. Individuals working part-time in the previous year are more likely to work in the current year as a result of receiving health insurance, though the coefficient is insignificant. Coefficients for part-time, full-time, and self-employed are also statistically insignificant. These part-time last year results should be taken with a caution as the sample size is too small to measure any but the strongest effects with precision.

\section{Robustness Checks}

In interpreting our results, we have assumed that the differential changes in veteran labor supply are directly attributable to the acquisition of public health insurance. As mentioned earlier, this causal interpretation is legitimate as long as no prior veteran-specific trend exists. We therefore must ensure that veteran and non-veteran labor market outcomes do not move relative to one another as a result of unobservables that are unrelated to VA policy. Confirming this lack of movement implies that changes in veteran labor supply actually result from gaining access to public health care.

To test for pre-existing trends that differentially impact veterans and non-veterans, we estimate equation (1) using pre-policy data. We choose the years 1992-1995 because this is a period when no major changes took place in the VA health care system. We code the years 1992 and 1993 as the "pre" years, and 1994 and 1995 as "post" years. As shown in Table 6, this falsification test reveals no pre-existing trend in veterans' labor supply choices relative to their non-veteran counterparts. The coefficient of interest (veteran*post) in these regressions is consistently small and statistically insignificant at standard levels. In some cases, the sign on the coefficient of interest is even the opposite of what we find in our main results. 31

Another concern is that there may be systematic differences between veterans and nonveterans that change over time. When we allow all controls to enter for veterans and nonveterans separately, the coefficients on the veteran interactions are typically insignificant, and our coefficient of interest is virtually unchanged, as demonstrated in Table 7, column (1). Additionally, we use propensity score matching to draw veteran and non-veteran

\footnotetext{
31 There may be concern that this falsification check passes because of a smaller sample size, although we are reassured that the signs of the coefficients are opposite those in our main results. To further allay this concern, we ran two other, similar specification checks. For the first, we used the entire sample universe and included the original interaction of veteran *post and an artificial "fakepost" dummy that is coded 1 after 1993. In this case, the coefficient on veteran*post is similar to results from Table 2 and the coefficient on veteran *fakepost is insignificant and close to zero for all outcomes, the result expected in the absence of confounding pre-existing trends. The second check randomly drops observations from the full sample so that the sample size is equivalent to that in Table 6. For this check, we find that the not working and part-time results are still significant and of similar magnitude to the results in Table 2.
} 
samples that are comparable based on observable characteristics. Results for the not-working outcome are shown in Table 7, column (2). This strategy also produces results that are qualitatively the same to those in our main regressions. A related concern is that the composition of the veteran sample changes over time, so we present results in Table 7, column (7) that are restricted by date of birth to years 1934-1947 rather than ages 55-64, and these results are also consistent with our main results. To summarize, these tests suggest that differential trends do not drive our results.

\section{Implications and Discussion}

To facilitate a comparison of the labor market effects of this insurance transfer to other changes in social insurance, we calculate labor supply elasticities. To do so, we must make several assumptions. First, we estimate the value of VA insurance to be equivalent to the single-coverage health insurance premium for workers in 2002 , or $\$ 3270.60^{32}$ multiplied by $102 \%$ (since COBRA allows employers to charge individuals $102 \%$ of these costs in order to cover administrative fees), giving a value of $\$ 3336.01$. The average income of workers in our sample (in 2002 dollars), dropping those with negative income, is $\$ 57,863$. The average income for all men ages 55-64 in the CPS sample, not conditional on having worked in the previous year, is $\$ 47,662$. By this calculation, VA provides an income transfer equivalent to (3336/57863) $=.06$ or $6 \%$ of the average individual's income in the sample conditioned on work, and (3336/47662) $=.07$ or $7 \%$ of the average individual's income in the unconditioned sample.

In our main regression results (Table 2), we find that individuals are $3.33 \%$ more likely to be not working as a result of gaining VA coverage. For the unconditioned sample, individuals are $2.7 \%$ more likely to be not working as a result of gaining access to VA health care. These results together imply a non-participation elasticity of .39 for all individuals and .56 for those in our regression universe. This is larger than the result of .16 found for Social Security and other retirement wealth for those currently in the labor force (Coile and Gruber 2007) and falls within the range from 0 to .8 found for disability insurance (see Chen and van der Klaauw 2008 for a discussion of the literature on DI). Individuals in our sample are $8.40 \%$ more likely to report working part-time as a result of gaining VA coverage, which corresponds to an elasticity of 1.4. For the unconditioned sample individuals are $10 \%$ more likely to report part-time work, also implying an elasticity of 1.4.

Our results are qualitatively similar to structural results which predict that not-working rates will increase when Medicare is expanded (e.g. Gustman and Steinmeier 1995, Rust and Phelan 1997), with the exception of Lumsdaine et al. (1994), which finds no effect of the expansion of Medicare upon retirement but cautions that their method of incorporating medical insurance biases them against finding a result. Our design also enables us to compare our quantitative results to some of the previous structural literature. The September 1999 CPS includes a veterans' supplement which allows us to distinguish newly eligible (i.e. priority group 7 - non-poor and non-disabled) veterans from all other veterans. Using this survey, we estimate that $70 \%$ of U.S. veterans transitioned from having no VA coverage to full coverage under this program. In light of our estimated 0.45 percentage point decrease in labor force participation, this implies that access to free health care lowers labor force participation by $0.45 / 0.7$ or 0.64 percentage points. This calculation is a lower-bound, however, to the extent that of the $70 \%$ who became newly eligible, some veterans may have been unaware of their eligibility. To estimate an upper bound labor supply effect, we assume that all veterans who remained un-enrolled were unaware of their eligibility. Thus, we

\footnotetext{
32 According to National Compensation Survey: Employee Benefits in Private Industry in the United States, 2002-2003, U.S. Dept. of Labor and Bureau of Labor Statistics.
} 
assume that roughly $25 \%$ of veterans were aware of their access to VA coverage. This implies that as an upper-bound, labor force participation would drop $4^{*} .45$ or 1.8 percentage points as a result of gaining non-employer based health insurance coverage. In response to new coverage receipt, this implies that access to free health insurance lowers labor force participation by $1.8 / .7$ or 2.57 percentage points. This upper-bound estimate is consistent with the findings of French and Jones (2008) who find that job exit would be 2.6 percentage points higher if all workers had health insurance that was not tied to their employers.

Similarly, for the unconditioned sample, we find a .98 percentage point decrease in labor force participation. This implies a lower-bound effect of a $.98 / .7=1.4$ percentage point decrease in labor force participation and an upper bound decrease of $(4 * .98) / .7=5.6$ percentage points because of new health insurance coverage. This upper bound is consistent with French and Jones' (2008) finding of a 6.0 percentage point decrease in total labor force participation for individuals aged 60-67 if health insurance is not tied to employment. Our range of estimates is also consistent with Blau and Gilleskie $(2006,2008)$ who find that labor force participation falls by .5 to 3.5 percentage points as a result of gaining health retiree insurance coverage (i.e. coverage not tied to employment).

Our methodology can also be used to make back-of-the-envelope comparisons about the likely effect of national health insurance on employment for this age group. If, instead of using the hazard rate (that is, instead of limiting to people who worked in the previous year), we estimate equation (1) on the full set of men aged 55-64, the coefficient on veteran*post for the not-working outcome is equal to .0098 with full controls and .0044 with limited controls. Given that the not-working rate for men in this age group in Canada is .4333 and in the United States is .3450 , the gap between the two countries is $.0883 .{ }^{33}$ Using this rough estimation, we find that between $.0044 / .0883$, or $5 \%$, and $.0098 / .0883$, or $11 \%$, of that gap can be explained by the availability of public health insurance in Canada.

Although these results suggest that employment for men in our sample decreases when these men are offered health insurance, the results from this study do not prove that offering health insurance will decrease employment overall. First, as noted earlier in the paper, health insurance may improve the productivity of the unhealthy on the margin of working by increasing their health capital or decreasing incentives to keep income low to qualify for means-tested assistance programs. ${ }^{34}$ The multinomial logit results support this possibility by showing a decrease in not-working and an increase in part-time work for those who were not working in the previous year.

Additionally, even if employment decreases for older men, general equilibrium effects may increase the labor supply of other groups. Our overall results are not inconsistent with Gruber and Hanratty (1995), which finds that total employment rises with the introduction of national health insurance. In this paper we are only examining the effects on men close to the end of their full-time work-lives; social norms may keep prime-aged males in the labor force regardless of the offer of outside health insurance. Given that US labor market laws protecting older workers reduce job separations for older men (Lahey 2008), insurance may result in more productive job matches by encouraging older workers on the margin to retire and be replaced by less-experienced (and thus less costly under an assumption of Lazear contracts) workers.

\footnotetext{
${ }^{33}$ Thanks to Kevin Milligan for the relevant statistics for Canada. These statistics were calculated from the Statistics Canada Labour Force Survey for the years 1998 to 2002 for men ages 55-64.

34 Additional general equilibrium effects may also increase the average age of workers at small firms and decrease it at large firms since small firms are less likely to offer health insurance. If these effects are large enough, the compensating wage differential at small firms may decrease.
} 
There may also be spillover effects on female labor supply because a wife may also alter her labor supply in response to her husband's acquisition of health insurance. ${ }^{35}$ Because wives in these cohorts are more likely than their husbands to have jobs with flexible hours, it is possible that a wife's hours may rise when a husband leaves a traditional 40-50 hour a week job, even if the income effect would dictate that total family labor supply would decrease. ${ }^{36}$ On the other hand, because retirement is often a joint decision, we might also expect a woman's labor force participation to decrease when her husband's decreases. While detailed empirical findings regarding these competing effects are outside the scope of this paper, our estimates suggest that for certain demographic groups, particularly those with lesseducation, the average wife's labor supply increases when her husband receives VA insurance. ${ }^{37}$ These spillover effects thus somewhat mitigate negative effects on national productivity from men leaving the labor force.

Overall social welfare may increase even if labor supply declines among some groups. For example, if this insurance allows unhealthy workers with liquidity constraints to cut down on full-time work, then the gains from improved marginal utility of those workers may outweigh the loss of their productive labor and the cost of the insurance.

\section{Conclusion}

In conclusion, we find that providing free comprehensive health insurance outside of employment decreases full-time work for older workers and increases both part-time work and non-work. Our finding of a decrease in self-employment for those with low levels of education implies that the income effect of public insurance receipt dominates the reduction in job-lock for these individuals. However, for those with higher levels of education for whom employment may be more attractive, self-employment increases, suggesting that the reduction in job-lock dominates the income effect for these groups. Thus, our results suggest that the job-lock effect dominates for more highly educated workers, who are arguably more productive. The income effect dominates for less educated workers, who are more likely to be unhealthy or credit-constrained. While a reduction in job-lock unambiguously increases labor market efficiency, the welfare implications of a decrease in labor supply because of the income effect are unclear. On the one hand, this may represent labor force exit by unhealthy individuals who are better off not working and may be replaced by more efficient new entrants to the labor force. On the other hand, if productive workers are being encouraged to exit the work force earlier than they otherwise would, the resulting impact on overall productivity may be negative. To the extent that younger workers subsidize national health insurance for older workers, the income effect on older people from universal coverage may be a reason that non-employment is higher for older people in countries with national health coverage. However, lower employment in these groups may be efficient to the extent that it allows for more productive sorting into work and retirement.

\section{Acknowledgments}

The research reported herein was pursuant to a grant from the U.S. Social Security Administration (SSA) funded as part of the Retirement Research Consortium (RRC). The findings and conclusions expressed are solely those of the authors and do not represent the views of SSA, any agency of the Federal Government or the RRC. This research was also supported by National Institute on Aging Grant T32-AG00186. We are grateful to Elizabeth Ananat, David Autor, Raj Chetty, Dora Costa, Todd Elder, Amy Finkelstein, Eric French, Jon Gruber, Jim Poterba, Tom Saving, Ebonya Washington, Julie Zissimopoulos and participants in the MIT Public Finance lunch, the SSA-RRC annual meetings, the Bush School, and the Upjohn Institute, as well as two anonymous reviewers for helpful

\footnotetext{
${ }^{35}$ Because wives are generally younger than their husbands, this feature of the VA creates a situation analogous to a household in which the husband reaches the age of Medicare eligibility before his wife does.

36 Thanks to Charlie Brown for suggesting this possibility.

37 These results are available from the authors upon request.
} 
comments and suggestions and to Alejandro Bras, Christina Causey, Banashwar Ghosh, Erin Harrison, and Rebecca Willis for excellent research assistance. All remaining errors are our own.

\section{Works Cited}

Angrist, Joshua D.; Chen, Stacet H. Long-term Consequences of Vietnam-Era Conscription: Schooling, Experience, and Earnings; NBER Working Paper W13411; 2007.

Araiza, Isabel. How alternative definitions of retirement and social class shape conclusions about the retired population. Boston College; 2004. Dissertation

Autor, David H.; Duggan, Mark G. Distinguishing Income from Substitution Effects in Disability Insurance. American Economic Review 2007;97(2):119-24.

Berkovec, James; Stern, Steven. Job Exit Behavior of Older Men. Econometrica 1991;59(1):189-210.

Blau, David M.; Gilleskie, Donna B. Health Insurance and Retirement of Married Couples. Journal of Applied Econometrics 2006;21(7):935-953.

Blau, David M.; Gilleskie, Donna B. The Role of Retiree Health Insurance in the Employment Behavior of Older Men. International Economics Review 2008;49(2):475-514.

Borjas, George. Welfare Reform, Labor Supply, and Health Insurance in the Immigrant Population. Journal of Health Economics 2003;22(6):933-58. [PubMed: 14604554]

Bound, John; Burkhauser, Richard V. Economic Analysis of Transfer Programs Targeted on People with Disabilities. In: Ashenfelter, Orley; Card, David, editors. Handbook of Labor Economics. Vol. 3. Elsevier Science; Amsterdam: 1999. p. 3417-3528.

Boyle, Melissa. Costs and Benefits of Elderly Prescription Drug Coverage: Evidence from Veterans' Health Care; Holy Cross Working Paper 08-03; 2008.

Boyle, Melissa. Health and Utilization Effects of Increased Access to Publicly Provided Health Care: Evidence from the U.S. Department of Veterans Affairs; Holy Cross Working Paper 09-02; 2009.

Chen, Susan; van der Klaauw, Wilbert. The Work Disincentive Effects of the Disability Insurance Program in the 1990s. Journal of Econometrics 2008;142(2):757-784.

Chetty, Raj. Moral Hazard versus Liquidity and Optimal Unemployment Insurance. Journal of Political Economy 2008;116(2):173-234.

Coile, Courtney. Retirement Incentives and Couples' Retirement Decisions. Topics in Economic Analysis and Policy 2004;4(1):1-28. Article 17.

Coile, Courtney C.; Gruber, Jonathan. Future Social Security Entitlements and the Retirement Decision. The Review of Economics and Statistics May;2007 89(2):234-246.

Currie, Janet; Gruber, Jonathan. Saving Babies: The Efficacy and Cost of Recent Changes in the Medicaid Eligibility of Pregnant Women. Journal of Political Economy 1996;104(6):1263-96.

Currie, Janet; Gruber, Jonathan. Public Health Insurance and Medical Treatment: The Equalizing Impact of the Medicaid Expansions. Journal of Public Economics 2001;82:63-89.

Department of Veterans Affairs. Fact Sheet: VA Health Care and the Medical Benefits Package. Office of Public Affairs and Media Relations; Washington, DC: Jul. 2002a

Department of Veterans Affairs. 2001 National Survey of Veterans: Final Report. 2002b. Retrieved January 25, 2010, from, http://www1.va.gov/vetdata/docs/survey_final.htm

Duggan, Mark; Rosenheck, Robert; Singleton, Perry. Federal Policy and the Rise in Disability Enrollment: Evidence for the VA's Disability Compensation Program; NBER Working Paper $12323 ; 2006$.

Finkelstein, Amy; McKnight, Robin. What did Medicare do? The initial impact of Medicare on mortality and out of pocket medical spending. Journal of Public Economics 2008;92(7):16441668 .

French, Eric; Jones, John B. The Effects Of Health Insurance And Self-Insurance on Retirement Behavior; Michigan Retirement Research Center Research Paper No. UM WP 2007-170; 2008.

Fronstin, Paul. Sources of Health Insurance and Characteristics of the Uninsured: Analysis of the March 2000 Current Population Survey. Employee Benefit Research Institute Issue Brief No. 228. 2000 
Greenberg, Greg A.; Rosenheck, Robert A. Compensation of Veterans with Psychiatric or Substance Abuse Disorders and Employment and Earnings. Military Medicine 2007;172(2):162-168. [PubMed: 17357771]

Gruber, Jonathan; Hanratty, Maria. The Labor-Market Effects of Introducing National Health Insurance: Evidence from Canada. Journal of Business \& Economic Statistics 1995;13(2):163173.

Gruber, Jonathan; Madrian, Brigitte C. Health Insurance Availability and the Retirement Decision. American Economic Review 1995;85(4):938-948.

Gruber, Jonathan; Madrian, Brigitte C. Health Insurance, Labor Supply, and Job Mobility: A Critical Review of the Literature; NBER Working Paper 8817; 2002.

Gustman, Alan L.; Steinmeier, Thomas L. Partial Retirement and the Analysis of Retirement Behavior. Industrial and Labor Relations Review 1984;37(3):403-415.

Gustman, Alan L.; Steinmeier, Thomas L. Retirement Measures in the Health and Retirement Study. Industrial Relations 1995;34(Supp)

Hurd, Michael.; McGarry, Kathleen. The Relationship Between Job Characteristics and Retirement; NBER Working Paper 4558; 1993.

Johnson, Richard W.; Davidoff, Amy J.; Perese, Kevin. Health Insurance Costs and Early Retirement Decisions. Industrial and Labor Relations Review 2003;56(4):716-729.

Karoly, Lynn A.; Rogowski, Jeannette A. The Effect of Access to Post-Retirement Health Insurance on the Decision to Retire Early. Industrial \& Labor Relations Review 1994;48:103-123.

Kiuila, Olga; Mieszkowski, Peter. The Effects of Income, Education and Age on Health. Health Economics 2007;16:781-798. [PubMed: 17238223]

Klein, Robert E.; Stockford, Donald D. Data on the Socioeconomic Status of Veterans and on VA Program Usage. 2001. http://www.va.gov/vetdata/docs/vp_special_reports.htm. Last accessed 4/7/09

Krueger, Alan B.; Meyer, Bruce D. Labor Supply Effects of Social Insurance. Handbook of Public Economics 2002;4:2327-92.

Lahey, Joanna N. Age Discrimination Laws and the Age Discrimination in Employment Act. Journal of Law and Economics 2008;51(3):433-460.

Le, Anh T. Empirical Studies of Self-Employment. Journal of Economic Surveys 1999;13(4):381-416.

Lichtenberg, Frank. The Effects of Medicare on Health Care Utilization and Outcomes. In: Garber, Alan, editor. Frontiers in Health Policy Research. Vol. 5. MIT Press; Cambridge, MA: 2002.

Lillard, Lee A.; Panis, Constantijn W. A. Marital Status and Mortality: The Role of Health. Demography 1996;33(3):313-27. [PubMed: 8875065]

Lucas, Robert E., Jr. On the Size Distribution of Business Firms. Bell Journal of Economics 1978;9(2): 508-523.

Lumsdaine, Robin L.; Stock, James H.; Wise, David A. Pension Plan Provisions and Retirement: Men and Women, Medicare, and Models. In: Wise, David A., editor. Studies in the Economics of Aging. University of Chicago Press; Chicago: 1994. p. 183-222.

Madrian, Brigitte C.; Beaulieu, Nancy D. Does Medicare Eligibility Affect Retirement?. In: Wise, DA., editor. Inquiries in the Economics of Aging. University of Chicago Press; Chicago: 1998. p. 109-131.

Maestas, Nicole. Back to Work: Expectations and Realizations of Work after Retirement. Journal of Human Resources. Forthcoming 2010.

Meyer, Bruce D.; Rosenbaum, Dan T. Welfare, The Earned Income Tax Credit, and The Labor Supply of Single Mothers. The Quarterly Journal of Economics 2001;116(3):1063-1114.

Moffitt, Robert; Wolfe, Barbara L. The Effect of the Medicaid Program on Welfare Participation and Labor Supply. Review of Economics and Statistics 1992;74(4):615-626.

Nelson, Charles T.; Mills, Robert J. The March CPS Health Insurance Verification Question and its Effect on Estimates of the Uninsured. US Census Bureau. 2001. http://www.census.gov/hhes/www/hlthins/verif.htm. Last Accessed 4/7/09 
Rogowski, Jeannette; Karoly, Lynn. Health insurance and retirement behavior: evidence from the health and retirement survey. Journal of Health Economics 2000;19(4):529-539. [PubMed: 11010239]

Ruhm, Christopher. Bridge Jobs and Partial Retirement? Journal of Labor Economics 1990;8(4):482501.

Rust, John; Phelan, Christopher. How Social Security and Medicare Affect Retirement Behavior in a World of Incomplete Markets. Econometrica 1997;65(4):781-831.

U.S. Department of Labor and Bureau of Labor Statistics. National Compensation Survey: Employee Benefits in Private Industry in the United States, 2002-2003. 2003

U.S. General Accounting Office. VA Health Care: Efforts to Improve Veterans' Access to Primary Care Services. Washington, DC: Apr 24. 1996 GAO/T-HEHS-96-134

U.S. General Accounting Office. Veterans' Affairs: Progress and Challenges in Transforming Health Care. Washington, DC: Apr 15. 1999 GAO/T-HEHS-99-109

U.S General Accounting Office. VA Health Care: Framework for Analyzing Capital Asset Realignment for Enhanced Services Decisions. Washington, DC: Aug. 2003 GAO-03-1103R

Winkler, Anne E. The Incentive Effects of Medicaid on Women's Labor Supply. Journal of Human Resources 1991;26(2):308-337.

Wolinsky, Frederic D.; Coe, Rodney M.; Mosely, Ray R., II; Homan, Sharon M. Veterans' and Nonveterans' Use of Health Services: A Comparative Analysis. Medical Care 1985;23(12):135871. [PubMed: 3910973]

Yelowitz, Aaron S. The Medicaid Notch, Labor Supply and Welfare Participation: Evidence from Eligibility Expansions. The Quarterly Journal of Economics 1995;110(4):909-940. 


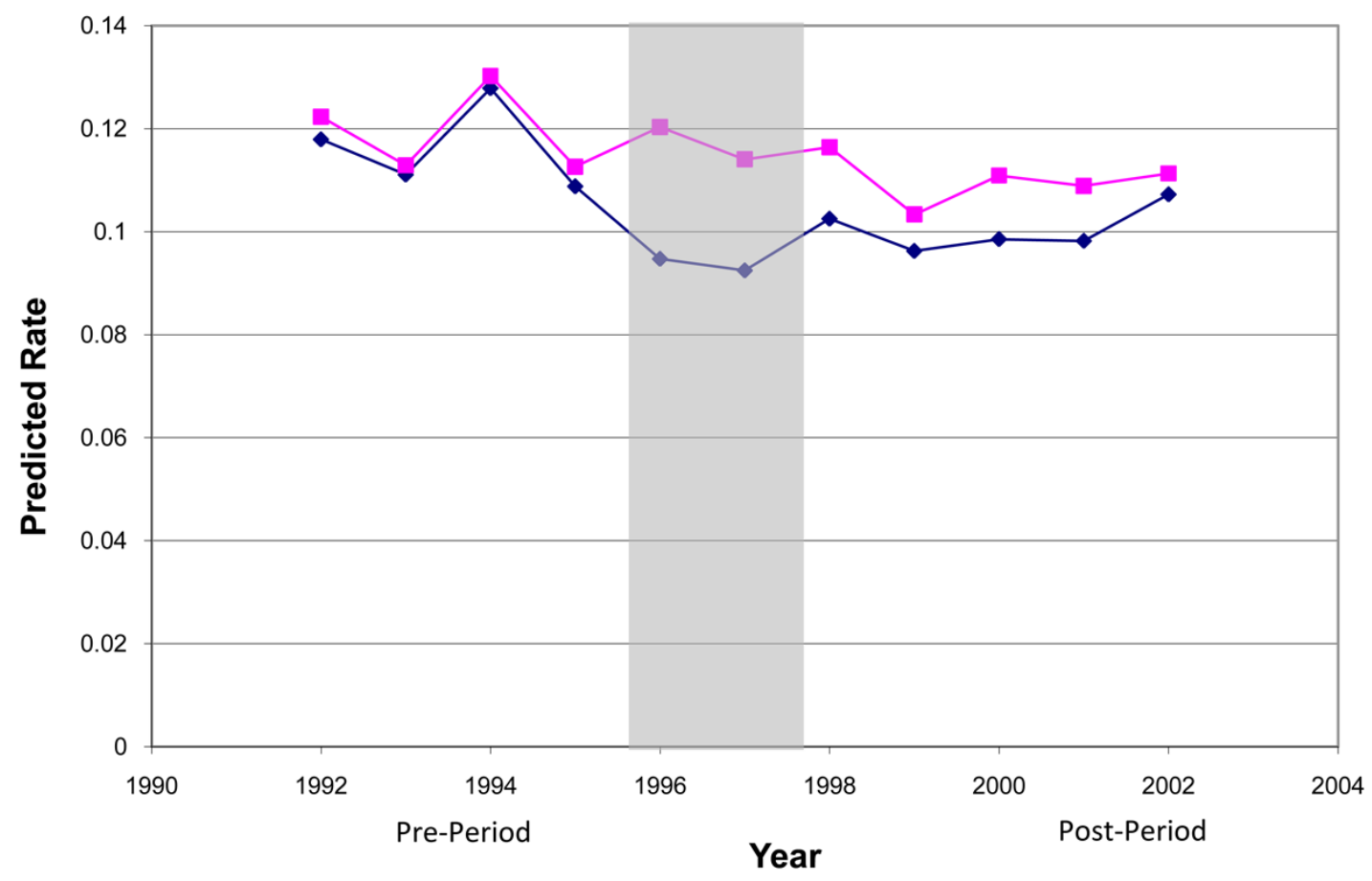

Figure 1a. Predicted Notworking Rates by Year and Veteran Status

This event study graph shows the predicted means trend for notworking male veterans and non-veterans, aged 55-64 using OLS regressions with indicator controls for age that compared veterans and non-veterans from 1992-2002. The shaded area represents the years of the rollout of the expansion. 

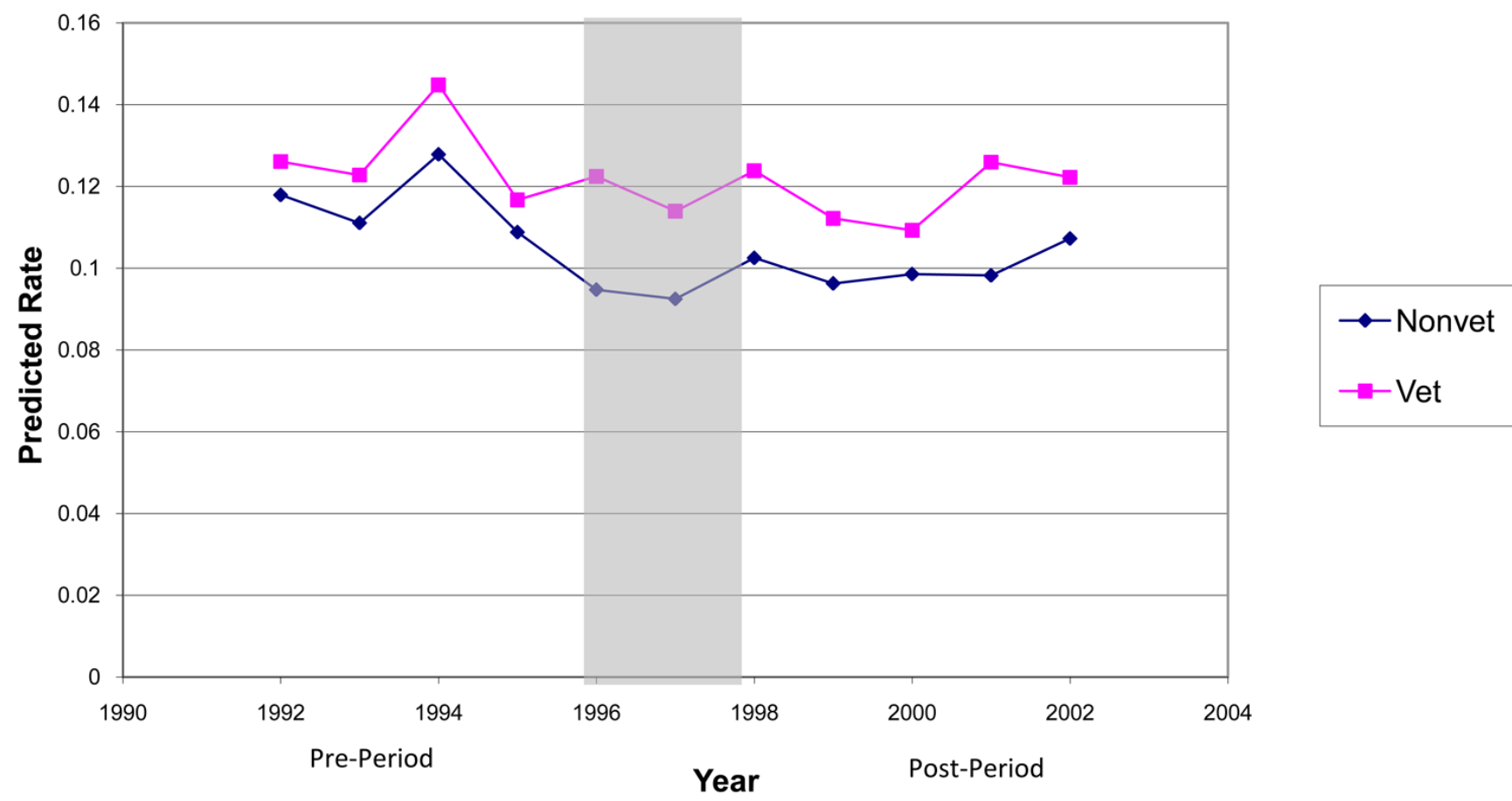

Figure 1b. Predicted Notworking Rates by Year and Veteran Status with Demographic Controls This event study graph shows the predicted means trend for notworking male veterans and non-veterans, aged 55-64 using OLS regressions with limited demographic controls (marital status, race, education level, age dummies, and division dummies) that compared veterans and non-veterans from 1992-2002. The shaded area represents the years of the rollout of the expansion. 
Table 1

Summary Statistics, CPS 1992-2002*

\begin{tabular}{|c|c|c|c|c|}
\hline & \multicolumn{2}{|c|}{ Veterans } & \multicolumn{2}{|c|}{ Non-Veterans } \\
\hline & $\begin{array}{c}\text { Pre } \\
(\mathrm{N}=9166)\end{array}$ & $\begin{array}{c}\text { Post } \\
(\mathrm{N}=9045)\end{array}$ & $\begin{array}{c}\text { Pre } \\
(\mathrm{N}=7517)\end{array}$ & $\begin{array}{c}\text { Post } \\
(\mathrm{N}=12252)\end{array}$ \\
\hline Age & 59.326 & 58.78 & 58.492 & 58.639 \\
\hline Married & 0.842 & 0.823 & 0.838 & 0.818 \\
\hline White & 0.937 & 0.921 & 0.864 & 0.86 \\
\hline No HS & 0.135 & 0.061 & 0.303 & 0.218 \\
\hline HS & 0.354 & 0.344 & 0.305 & 0.29 \\
\hline Some College & 0.237 & 0.289 & 0.145 & 0.172 \\
\hline College Grad & 0.161 & 0.175 & 0.112 & 0.153 \\
\hline Grad School & 0.113 & 0.131 & 0.135 & 0.167 \\
\hline Pension Plan & 0.529 & 0.57 & 0.476 & 0.504 \\
\hline Empl. HI Plan & 0.686 & 0.709 & 0.637 & 0.65 \\
\hline Northeast & 0.236 & 0.219 & 0.264 & 0.222 \\
\hline Midwest & 0.257 & 0.24 & 0.239 & 0.229 \\
\hline South & 0.295 & 0.291 & 0.295 & 0.312 \\
\hline West & 0.212 & 0.25 & 0.202 & 0.237 \\
\hline Not Working & 0.135 & 0.115 & 0.116 & 0.101 \\
\hline Self-Employed & 0.213 & 0.182 & 0.228 & 0.206 \\
\hline Part Time & 0.106 & 0.102 & 0.091 & 0.088 \\
\hline \multicolumn{5}{|l|}{ Occupations: } \\
\hline Prof/Management & 0.308 & 0.328 & 0.285 & 0.329 \\
\hline Tech/Sales/Cleric & 0.213 & 0.21 & 0.167 & 0.162 \\
\hline Service & 0.08 & 0.082 & 0.094 & 0.093 \\
\hline Farming & 0.051 & 0.034 & 0.075 & 0.057 \\
\hline Craftsman & 0.175 & 0.18 & 0.175 & 0.166 \\
\hline Operator & 0.172 & 0.166 & 0.204 & 0.193 \\
\hline \multicolumn{5}{|l|}{ Industries: } \\
\hline Agric/Mining & 0.051 & 0.036 & 0.071 & 0.058 \\
\hline Construction & 0.078 & 0.084 & 0.09 & 0.092 \\
\hline Manufacturing & 0.19 & 0.171 & 0.211 & 0.184 \\
\hline Transport/Commun & 0.095 & 0.115 & 0.078 & 0.079 \\
\hline Trade & 0.147 & 0.138 & 0.159 & 0.144 \\
\hline Finance/Real estate & 0.057 & 0.06 & 0.051 & 0.056 \\
\hline Business/Repair & 0.05 & 0.059 & 0.049 & 0.059 \\
\hline Personal & 0.035 & 0.03 & 0.034 & 0.039 \\
\hline Public & 0.061 & 0.071 & 0.034 & 0.036 \\
\hline Professional & 0.152 & 0.153 & 0.155 & 0.182 \\
\hline
\end{tabular}




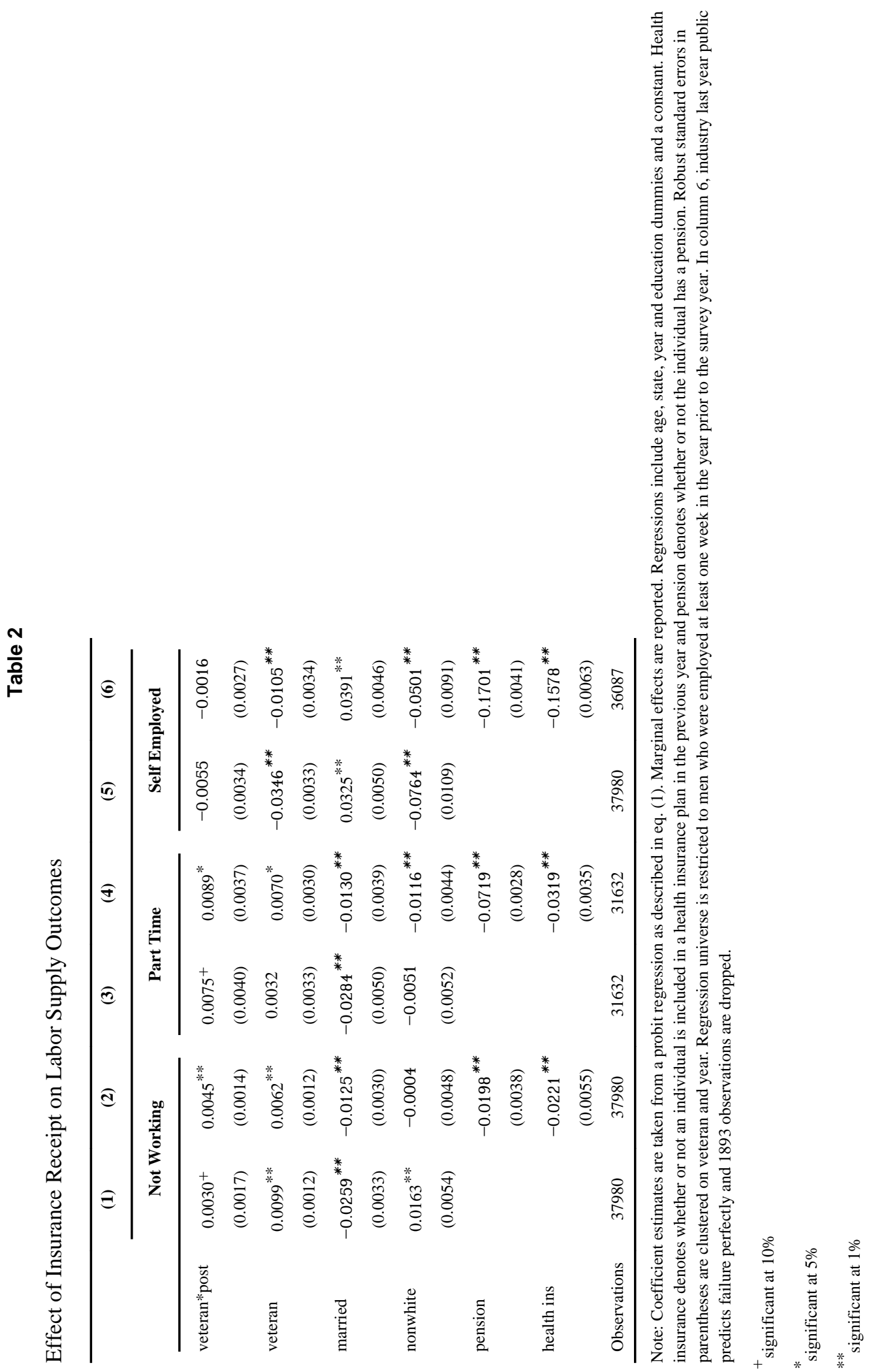




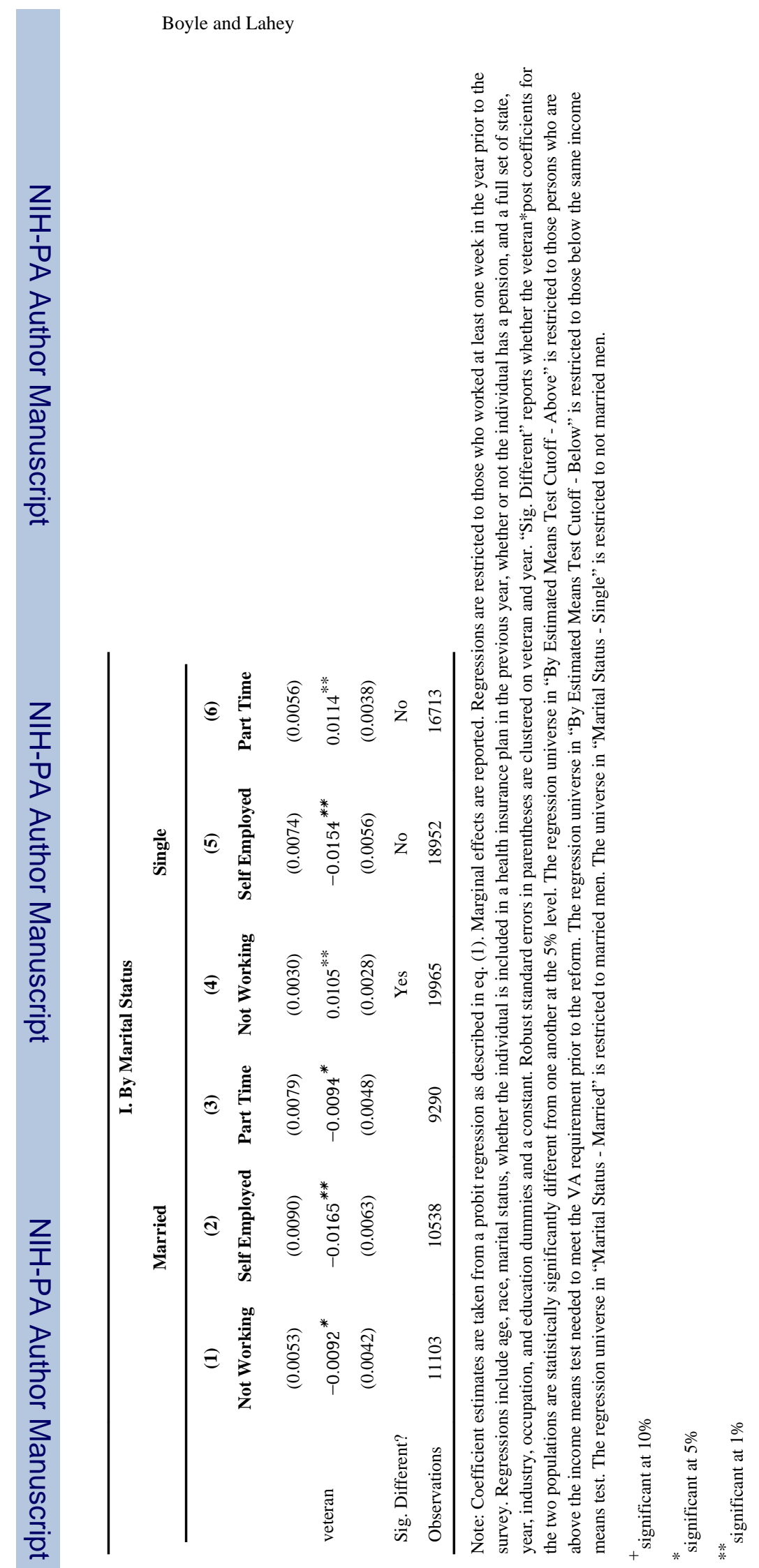

J Public Econ. Author manuscript; available in PMC 2011 August 1. 
Table 4

More Results by Group Status

\begin{tabular}{|c|c|c|c|c|}
\hline & \multicolumn{4}{|c|}{ I. Self-Employment: By Education Level } \\
\hline & \multicolumn{2}{|c|}{ High school or less } & \multicolumn{2}{|c|}{ Some college or more } \\
\hline & (1) & (2) & (3) & (4) \\
\hline \multirow[t]{2}{*}{ veteran*post } & $-0.0256^{* *}$ & $-0.0155^{* *}$ & $0.0218^{*}$ & $0.0326^{* *}$ \\
\hline & $(0.0056)$ & $(0.0043)$ & $(0.0091)$ & $(0.0080)$ \\
\hline \multirow[t]{2}{*}{ veteran } & $-0.0293^{* *}$ & -0.0025 & $-0.0752^{* *}$ & $-0.0531^{* *}$ \\
\hline & $(0.0044)$ & $(0.0046)$ & $(0.0079)$ & $(0.0061)$ \\
\hline Full controls? & No & Yes & No & Yes \\
\hline \multirow[t]{4}{*}{ Observations } & 18934 & 18423 & 13771 & 12784 \\
\hline & \multicolumn{4}{|c|}{ II. Not Working: By Wife's Employment Status } \\
\hline & \multicolumn{2}{|c|}{ Married Men without Working Wives } & \multicolumn{2}{|c|}{ Single Men and Men with Working Wives } \\
\hline & (1) & (2) & (3) & (4) \\
\hline \multirow[t]{2}{*}{ veteran*post } & -0.0091 & $-0.0171^{* *}$ & $0.0093^{*}$ & $0.0131^{* *}$ \\
\hline & $(0.0090)$ & $(0.0060)$ & $(0.0040)$ & $(0.0032)$ \\
\hline \multirow[t]{2}{*}{ veteran } & 0.0077 & $0.0163^{* *}$ & $0.0082^{*}$ & 0.0025 \\
\hline & $(0.0073)$ & $(0.006)$ & $(0.0034)$ & $(0.0045)$ \\
\hline Full controls? & No & Yes & No & Yes \\
\hline Observations & 11756 & 11756 & 25814 & 25814 \\
\hline
\end{tabular}

Note: Coefficient estimates are taken from a probit regression as described in eq. (1). Marginal effects are reported. Regressions are restricted to those who worked at least one week in the year prior to the survey. Regressions without the full controls include age, race, marital status, and a full set of state, year, education and age dummies. Full controls also include whether the individual is included in a health insurance plan or pension plan in the previous year and a full set of industry and occupation dummies. Robust standard errors in parentheses are clustered on veteran and year. Some college or more includes some college and college educated, those with higher education are not included.

+ significant at $10 \%$

significant at $5 \%$

s** significant at $1 \%$ 
Table 5

Marginal Effects of Multinomial Logit

\begin{tabular}{lcccc}
\hline & \multicolumn{3}{c}{ Regression Universe } \\
\cline { 2 - 3 } & \multicolumn{1}{c}{ Not working last year } & Full time last year & Part time last year \\
\cline { 2 - 2 } Not Working & $-0.00206^{* *}$ & $(\mathbf{2})$ & $(\mathbf{3})$ \\
& $(0.0008)$ & $0.01073^{* *}$ & -0.00158 \\
Part Time for employer & $0.00191^{* *}$ & $(0.00169)$ & $(0.00607)$ \\
& $(0.00073)$ & 0.00064 & 0.02435 \\
Self Employed & $0.00017^{+}$ & $(0.00107)$ & $(0.02954)$ \\
& $(0.00009)$ & 0.00058 & -0.02593 \\
Full Time for employer & -0.00002 & $(0.00068)$ & $(0.0292)$ \\
& $(0.00026)$ & $-0.01196^{* *}$ & 0.00315 \\
Observations & 13,835 & $(0.00223)$ & $(0.01839)$ \\
\hline
\end{tabular}

Note: Estimates are from multinomial logit regressions for three different population subsets: worked full time last year, worked part time last year, and did not work last year. Not working last year is limited to working 0 weeks. Results from limiting to 2 weeks of work or fewer are similar.

Marginal effects for coefficient on veteran*post are reported for each outcome (not working, part time for an employer, self-employed, full time for an employer). Regressions estimate equation (2) by multinomial logit. Controls include age, race, marital status, whether the individual is included in a health insurance plan and pension plan in the previous year, and a full set of state, year, industry, occupation, and education dummies and a constant. Column (1) does not include occupation last year controls.

\footnotetext{
${ }^{+}$significant at $10 \%$

significant at $5 \%$

**

significant at $1 \%$
} 


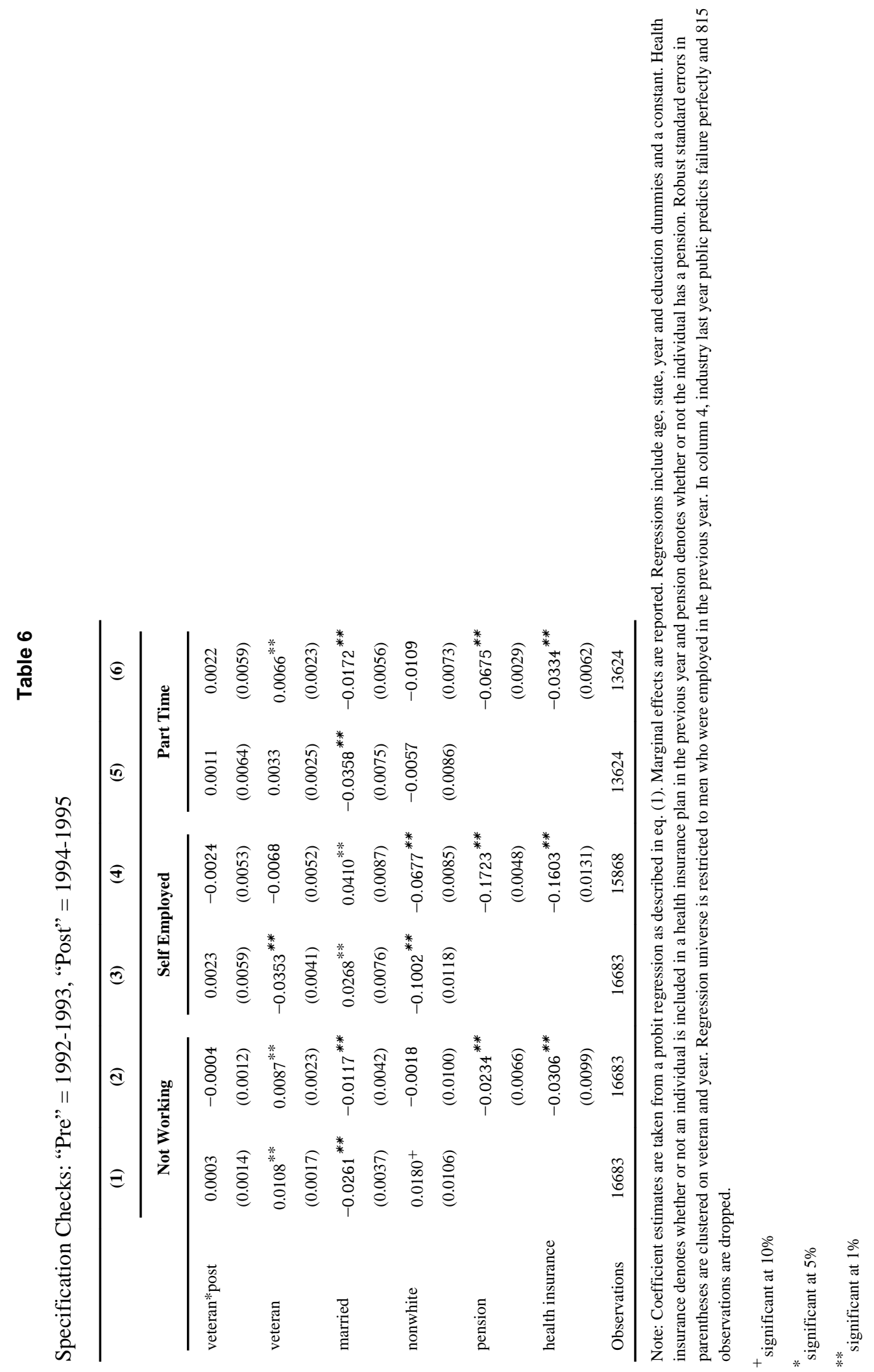




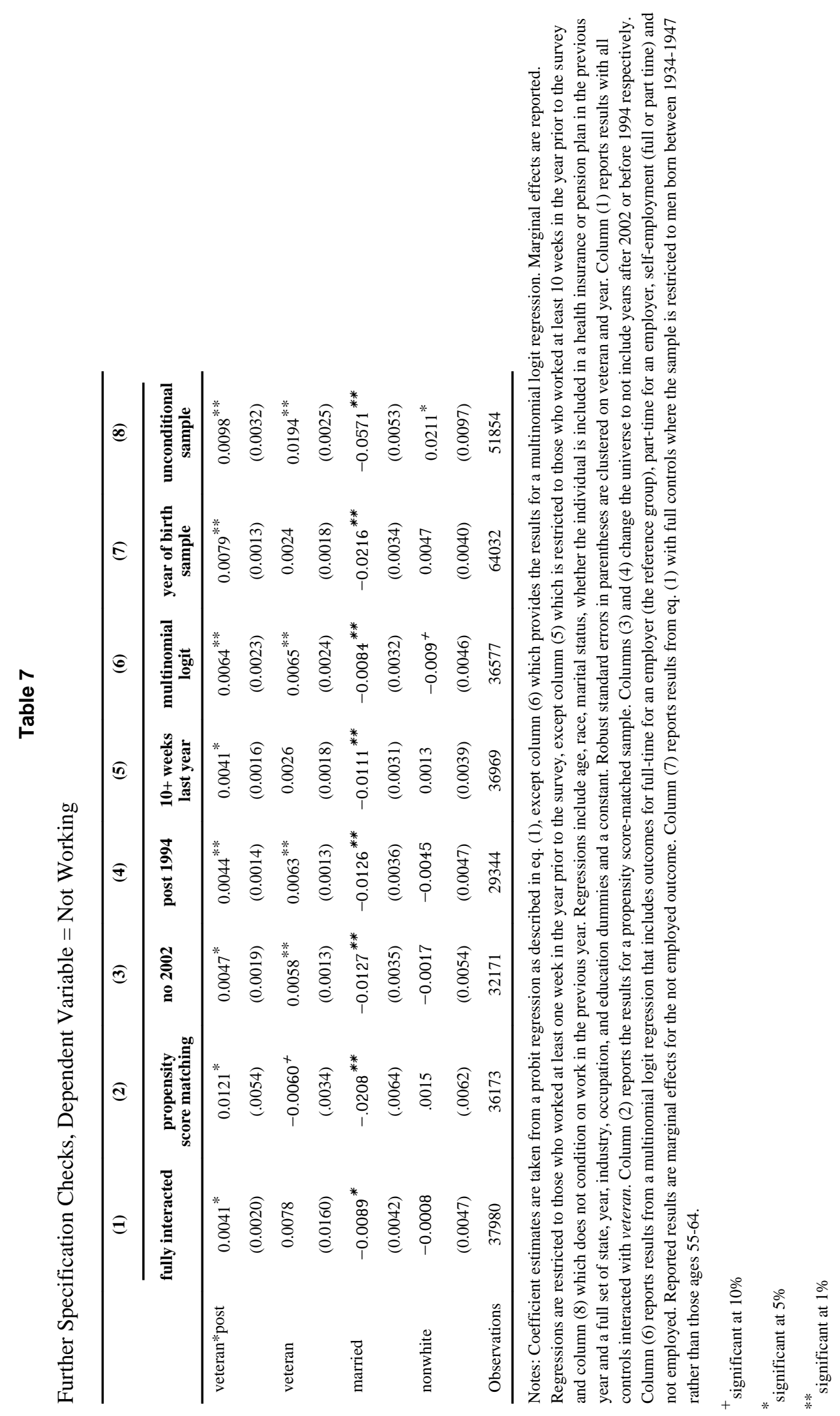

J Public Econ. Author manuscript; available in PMC 2011 August 1. 